WellBeing International

WBI Studies Repository

$8-2002$

\title{
Within-Litter Birth Weight Variation in the Domestic Pig and its Relation to Pre-Weaning Survival, Weight Gain, and Variation in Weaning Weights
}

\author{
Barry N. Milligan \\ McGill University \\ David Fraser \\ University of British Columbia \\ Donald L. Kramer \\ McGill University
}

Follow this and additional works at: https://www.wellbeingintlstudiesrepository.org/ontoge

Part of the Animal Studies Commons, Developmental Biology Commons, and the Other Animal

Sciences Commons

\section{Recommended Citation}

Milligan, B. N., Fraser, D., \& Kramer, D. L. (2002). Within-litter birth weight variation in the domestic pig and its relation to pre-weaning survival, weight gain, and variation in weaning weights. Livestock Production Science, 76(1), 181-191.

This material is brought to you for free and open access by WellBeing International. It has been accepted for inclusion by an authorized administrator of the WBI Studies Repository. For more information, please contact wbisr-info@wellbeingintl.org.

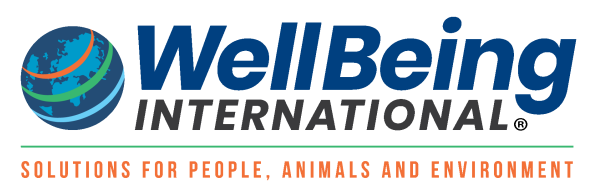




\title{
Within-Litter Birth Weight Variation in the Domestic Pig and its Relation to Pre-Weaning Survival, Weight Gain, and Variation in Weaning Weights
}

\author{
Barry N. Milligan ${ }^{1}$, David Fraser ${ }^{2}$, Donald L. Kramer $^{1}$ \\ ${ }^{1}$ McGill University \\ ${ }^{2}$ University of British Columbia
}

\section{KEYWORDS}

pig, birth weight, weaning

\begin{abstract}
To determine the relationship between within-litter birth weight variation and pre-weaning survival and weight gain, and to provide practical guidance on fostering low-birth-weight piglets, we analyzed piglet survival and weight gain in litters of piglets from 52 sows followed through eight consecutive parities. Litters with high variation in birth weight had more deaths, especially if the litter's mean birth weight was low. High variation in birth weight was also associated with high variation in weaning weight, but was not significantly related to mean weaning weight. Piglets with birth weights well below the range of most of the litter ('low-birth-weight piglets') were more likely to die than their litter-mates, but their weight gains were normal for their birth weight if they survived. These piglets experienced particularly low survival in larger litters and litters from sows of sixth parity or older. Litters containing low-birth-weight piglets started, on average, with more piglets born alive and had a lower pre-weaning survival (with the majority of deaths being low-birth-weight piglets), but did not wean significantly more piglets than litters without low-birth-weight piglets. The majority of litters had a negatively skewed distribution of birth weights, with more piglets well below the mean than well above it. Our data are consistent with the hypothesis that high variation in birth weight contributes to reduced survival, at least for litters of low mean birth weight, and to variable weaning weights. Our data also support the hypothesis that in terms of survival, small piglets have a competitive disadvantage compared to their heavier litter-mates, a disadvantage that is exacerbated in large litters and litters from older sows. Our data suggest that selection for increased litter size that results in more low-birth-weight piglets per litter may not be beneficial unless measures are undertaken to improve the survival of low-birth-weight piglets.
\end{abstract}

\section{Introduction}

There is relatively little solid evidence about birth weight variation within litters and its effects on piglet survival and weight gain. The impact is often inferred from the negative relationship between survival and birth weight variation (Fahmy et al., 1978; Pettigrew et al., 1986; English et al., 1977). However, the 
correlation between birth weight variation and survival may be confounded by the tendency for litters with variable birth weights to be larger and have more low-birth-weight piglets (Van der Lende and de Jager, 1991) and to be from older parity sows (Pettigrew et al., 1986). Experimental studies, which have controlled for these confounded variables, have produced conflicting results. A study of birth weight variation between litters with similar mean birth weight found that pre-weaning survival was higher in litters of 11 piglets with reduced birth weight variation (English et al., 1977); however, another experiment found that in healthy litters of average birth weight, the amount of variation in birth weight had little effect on piglet survival or weight gain (Milligan et al., 2001a).

Litters with high levels of birth weight variation are claimed to have lower survival because of direct competitive exclusion of light litter-mates from access to functional and productive teats (English et al., 1977; English and Morrison, 1984). Larger piglets may also compete indirectly with their litter-

mates by stimulating and/or draining their teats more effectively and may thus direct a larger fraction of hormones and nutrients involved in milk production to their respective teats (Fraser et al., 1979; Thompson and Fraser, 1986; Algers et al., 1991). Such indirect competition between litter-mates may explain why the differences in body weight at birth are often maintained or increased throughout lactation.

Pig producers are commonly encouraged to intervene so that less competitive piglets will survive and achieve adequate milk intake. One common strategy is to cross-foster piglets between litters (English, 1998) in order to equalize the number of pigs per litter and minimize birth weight variation (Straw et al., 1998). Cross-fostering to ensure that low-birth-weight piglets compete with litter-mates of similar size is particularly encouraged because low-birth-weight piglets are presumed to be at greatest risk of being excluded from the udder by heavier litter-mates (English, 1998). Small piglets are presumed to be at even greater risk if there are many litter-mates because of the increased number of competitors, and with older sows because of more variable access to functional teats (Cutler et al., 1999).

There is also little direct evidence that litter-mate size has an impact on the weight gain or survival of lowbirth-weight piglets. In one study, fostering low-birth-weight pigs into litters with other low-birth-weight pigs was found to improve their survival and weight gain relative to similar-sized pigs that were not fostered (Marcatti Neto, 1986), but a similar study found no such effect (Aherne, 1999). In our research, raising low-birth-weight piglets with much heavier litter-mates, versus slightly heavier litter mates, resulted in slightly more deaths among low birth-weight piglets, but had no effect on total deaths in the litter or on the weight gain of low-birth-weight piglets (Milligan et al., 2001b). However, because that study excluded very light and unhealthy piglets, litters with greater than 12 piglets, and sick sows, it may have eliminated those piglets most likely to be disadvantaged by intense sibling competition.

In this paper, we analyzed piglet survival and weight gain in relation to piglet birth weight and within-litter birth weight variation in order: (1) to describe patterns of within-litter birth weight variation, and (2) determine the effect of within-litter birth weight variation on pre-weaning survival, weight gain, and variation in weaning weights.

\section{Materials and methods}

The study used 416 Yorkshire and Yorkshire $\times$ Landrace litters from the Centre for Food and Animal Research herd near Ottawa. The litters represented the first eight litters born to each of 52 sows between 1981 and 1995. Sows were housed throughout farrowing and lactation in standard far rowing crates (0.5 $\mathrm{m} \times 2 \mathrm{~m})$ in pens $(1.5 \mathrm{~m} \times 2 \mathrm{~m})$. All sows with complete records for their first eight litters were included. Piglets were weighed to the nearest $5 \mathrm{~g}$ when they became ready for initial processing between 08:00 and 14:00 h. Weight at weaning (on the Thursday closest to the day when the piglets reached 28 days of 
age) was recorded for each piglet that survived the suckling period. One hundred and eighty-two litters were altered by the addition or removal of piglets, after birth weights were obtained but before weaning, for routine cross fostering or experimental purposes. Both altered and unaltered litters were included in analysis of variables recorded at birth (total number of piglets born, number of live piglets, percent of piglets born alive, mean birth weight, birth weight coefficient of variation (CV) and parity). Analysis of variables recorded at weaning (number of piglets weaned, mean weaning weight, weaning weight CV, and percent survival to weaning) did not include the 182 altered litters. Variables recorded at birth did not differ significantly between the altered and unaltered litters as determined by analysis of variance. Unless noted otherwise, all statistical analysis was carried out using SYSTAT MGLH (Wilkinson, 1990).

Simple Pearson correlations were calculated among number of live piglets, mean birth weight, and birth weight CV and the dependent variables percent survival to weaning, mean weaning weight, and weaning weight CV.

Analysis of variance was used to study the effects of parity on the total number of piglets born, number of piglets born alive, percent of piglets born alive, mean birth weight, and birth weight CV. Sows were divided into four parity groups representing gilts (parity 1), second parity sows (2), middle-aged sows (35), and old sows (6-8). The effect of parity was tested against a litter error term after removing the effect of individual sows as a blocking term. For analysis of percent of piglets born alive, mean birth weight, and birth weight CV, the effect of parity number was tested after adjusting for the number of piglets born.

Analysis of covariance (ANCOVA) was used to assess the relationship between percent survival to weaning and other variables: number of piglets born alive, mean birth weight, birth weight $\mathrm{CV}$, and the interaction of mean birth weight and birth weight CV. ANCOVA was also used to assess the relationship between weaning weight $\mathrm{CV}$ and other variables: number of piglets born alive, mean birth weight, birth weight $\mathrm{CV}$, and mean weaning weight. After entry of the above covariates the relationship of parity to percent survival to weaning, mean weaning weight, and weaning weight CV was also assessed. All effects were tested against a litter error term after removal of the sow effect as a blocking term.

In a separate analysis piglets were divided into two 'birth weight classes' (Robert et al., 1995). Many litters included one or more piglets which either: (1) weighed at least $300 \mathrm{~g}$ less than the litter's mean birth weight, or (2) weighed 200-300 g less than the litter's mean birth weight and at least $100 \mathrm{~g}$ less than the immediately larger member of the litter. These were identified as 'low-birth-weight piglets'. All other piglets in these litters were classed as 'higher-birth-weight piglets'. This classification was designed by Robert et al. (1995) to simulate the judgement that a stock person might make in identifying piglets with birth weights well below the range of most of the litter. There were 41 litters where no animals met the criterion for low-birth weight piglets; these litters were omitted from this analysis. The remaining 193 litters included from 1 to 5 low-birth-weight piglets, with an average of 2.1. Weight gain and survival data were analyzed by analysis of covariance with piglet birth weight class (low- or higher-birth-weight) blocked within litters. In this analysis, birth weight, followed by birth weight class and its interactions with litter size and parity, were tested against an error term based on within-litter variation. In this way, we could assess the additional contribution of birth weight class to weight gain and survival after taking actual birth weight into account. All effects were tested after removal of the sow effect as a blocking term.

Analysis of variance was used to test whether there were differences between litters with and without lowbirth-weight piglets in number of piglets born alive, mean birth weight, birth weight $\mathrm{CV}$, percent survival to weaning, number of piglets weaned, mean weaning weight, and weaning weight $\mathrm{CV}$. The model included litter 'classification' (litters with or without low-birth-weight piglets) with the sow entered as a blocking term. 
Standardized or $z$-scores for each piglet birth weight $x_{i}$ were calculated as

$$
z=\left(x_{i}-\mu\right) / \sigma
$$

where $\mu$ is the litter mean and $\sigma$ is the standard deviation (S.D.) of weights in the litter. The $z$-score indicates how many standard deviations from the litter mean the $x_{i}$ value is located.

Table 1. Correlations between percent survival to weaning, mean weaning weight, weaning weight $\mathrm{CV}$, and three independent variables (number of live piglets, mean birth weight, and birth weight CV)

\begin{tabular}{|lccccc|}
\hline Variable & $\begin{array}{c}\text { Mean birth } \\
\text { weight } \mathbf{( k g )}\end{array}$ & $\begin{array}{c}\text { Birth weight } \\
\text { CV }\end{array}$ & $\begin{array}{c}\text { Percent survival } \\
\text { to weaning }\end{array}$ & $\begin{array}{c}\text { Mean weaning } \\
\text { weight }(\mathbf{k g})\end{array}$ & $\begin{array}{c}\text { Weaning weight } \\
\text { CV }\end{array}$ \\
\hline Number of live piglets & $-0.458^{\star \star}$ & $0.394^{\star \star}$ & $-0.272^{\star *}$ & $-0.348^{\star \star}$ & $0.370^{\star \star}$ \\
Mean birth weight $(\mathrm{kg})$ & - & $-0.491^{\star \star}$ & $0.429^{\star \star}$ & $0.168^{\star}$ & $-0.235^{\star \star}$ \\
Birth weight CV & - & - & $-0.344^{\star \star}$ & -0.087 & $0.398^{\star \star}$ \\
\hline
\end{tabular}

${ }^{*} P<0.001 ;{ }^{*} P=0.01$.

Table 2. Mean ( \pm S.E.) measures at birth and weaning for first parity, second parity, middle-aged (parity 3-5), and old (parity 6-8) sows

\begin{tabular}{|lcccc|}
\hline Variable & \multicolumn{3}{c|}{ Parity } \\
\cline { 2 - 5 } & $\mathbf{1}$ & $\mathbf{2}$ & $\mathbf{3 - 5}$ & $\mathbf{6 - 8}$ \\
\hline Number of pigs born & $9.5 \pm 0.3 \mathrm{a}^{*}$ & $9.8 \pm 0.3 \mathrm{a}$ & $11.8 \pm 0.2 \mathrm{~b}$ & $11.7 \pm 0.3 \mathrm{~b}$ \\
Number of pigs born alive & $9.0 \pm 0.3 \mathrm{a}$ & $9.3 \pm 0.3 \mathrm{ab}$ & $10.8 \pm 0.2 \mathrm{c}$ & $10.1 \pm 0.2 \mathrm{~b}$ \\
Percent of pigs born dead & $5.1 \pm 1.5 \mathrm{a}$ & $4.9 \pm 1.2 \mathrm{a}$ & $7.7 \pm 0.8 \mathrm{a}$ & $12.3 \pm 1.0 \mathrm{~b}$ \\
Mean birth weight $(\mathrm{kg})$ & $1.32 \pm 0.03 \mathrm{a}$ & $1.47 \pm 0.03 \mathrm{~b}$ & $1.41 \pm 0.02 \mathrm{~b}$ & $1.39 \pm 0.02 \mathrm{~b}$ \\
Birth weight CV & $0.15 \pm 0.01$ & $0.16 \pm 0.01$ & $0.18 \pm 0.01$ & $0.19 \pm 0.01$ \\
Number of pigs weaned & $8.4 \pm 0.4$ & $9.2 \pm 0.3$ & $9.9 \pm 0.2$ & $9.0 \pm 0.2$ \\
Mean weaning weight $(\mathrm{kg})$ & $7.71 \pm 0.22$ & $8.18 \pm 0.21$ & $7.78 \pm 0.15$ & $7.92 \pm 0.11$ \\
Weaning weight CV & $0.13 \pm 0.01 \mathrm{a}$ & $0.15 \pm 0.01 \mathrm{ab}$ & $0.18 \pm 0.01 \mathrm{~b}$ & $0.18 \pm 0.1 \mathrm{~b}$ \\
Percent survival to weaning & $92.9 \pm 3.0$ & $96.8 \pm 1.3$ & $93.0 \pm 1.0$ & $89.9 \pm 1.2$ \\
\hline
\end{tabular}

${ }^{a}$ If values (within each variable set) have no letter or the same letter they do not differ significantly after adjustment for covariates $(P>0.05)$.

Fig. 1. Percent survival to weaning (mean \pm S.E.) of piglets in litters divided according to birth weight $\mathrm{CV}$, shown for litters whose mean birth weight was low $(<1.3 \mathrm{~kg})$, medium $(1.3-1.5 \mathrm{~kg})$ or high $(>1.5 \mathrm{~kg})$.

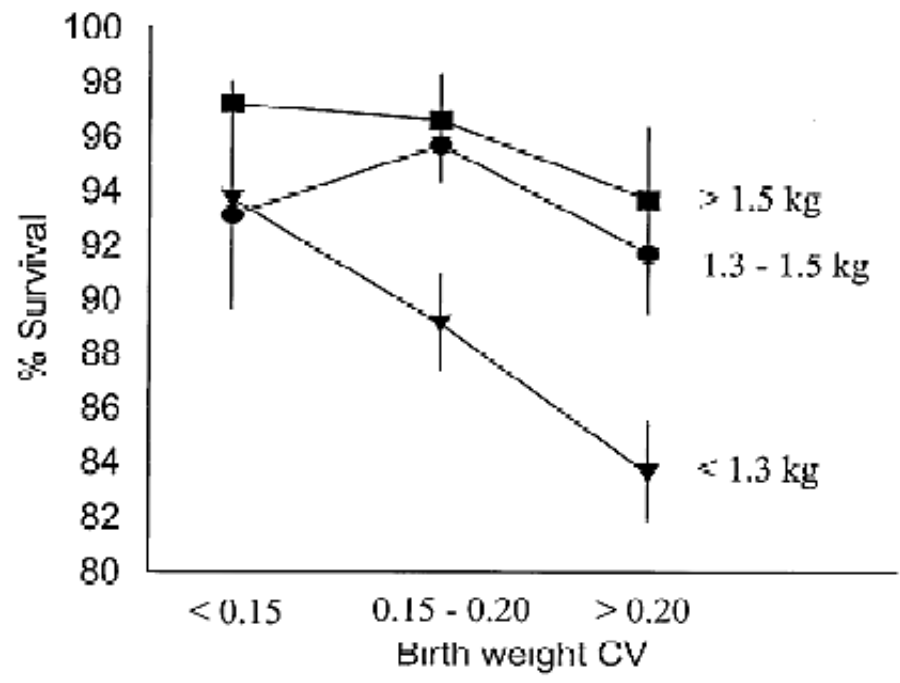


Table 3. Number of piglets $(n)$, mean birth weight $(\mathrm{kg})$, mean weaning weight $(\mathrm{kg})$ and percentage that survived of low- and higher-birth-weight piglets, divided according to litter size and parity

\begin{tabular}{|c|c|c|c|c|c|c|c|c|c|}
\hline & & \multicolumn{4}{|c|}{ Low-birth-weight } & \multicolumn{4}{|c|}{ Higher-birth-weight } \\
\hline & & $n$ & $\begin{array}{c}\text { Mean } \\
\text { birth } \\
\text { weight }\end{array}$ & $\begin{array}{c}\text { Mean } \\
\text { wean } \\
\text { weight }\end{array}$ & \% Survival & $n$ & $\begin{array}{c}\text { Mean } \\
\text { birth } \\
\text { weight }\end{array}$ & $\begin{array}{c}\text { Mean } \\
\text { wean } \\
\text { weight }\end{array}$ & \% Survival \\
\hline \multirow[t]{3}{*}{ Litter size } & $\leq 9$ & 55 & 1.05 & 7.11 & 83.6 & 207 & 1.57 & 8.91 & 92.3 \\
\hline & $9-11$ & 209 & 1.00 & 6.51 & 79.9 & 809 & 1.50 & 8.15 & 95.9 \\
\hline & $\geq 12$ & 132 & 0.90 & 5.91 & 63.1 & 577 & 1.38 & 7.56 & 91.9 \\
\hline \multirow[t]{5}{*}{ Parity } & 1 & 28 & 0.91 & 6.02 & 75.0 & 136 & 1.36 & 7.99 & 89.7 \\
\hline & 2 & 38 & 0.95 & 6.39 & 84.2 & 158 & 1.50 & 8.28 & 97.5 \\
\hline & $3-5$ & 160 & 1.00 & 6.42 & 78.2 & 597 & 1.49 & 8.03 & 94.5 \\
\hline & $6-8$ & 170 & 0.96 & 6.64 & 68.8 & 702 & 1.46 & 8.17 & 93.6 \\
\hline & Total & 396 & 0.97 & 6.39 & 74.5 & 1593 & 1.47 & 8.04 & 94.0 \\
\hline
\end{tabular}

The Kolmogorov-Smirnov one-sample test (SYSTAT NPAR; Wilkinson, 1990) was used with each litter to test whether the original birth weights departed from a normal distribution. Probability plots and frequency distributions were graphed using SYSTAT SYGRAPH for all litters with distributions differing significantly from normal (Wilkinson, 1990). The skewness value was also calculated for each litter. Skewness is a measure of symmetry of a distribution (Tabachnick and Fidell, 1989). When a distribution is normal, skewness values are zero. A negative skewness value indicates that the majority of piglet birth weights were above the litter mean while a minority had birth weights substantially below. A positive skewness value indicates that the majority of birth weights were below the litter mean while a minority had birth weights substantially above.

\section{Results}

The number of live-born piglets in a litter was negatively correlated with mean piglet birth weight and positively correlated with the CV of litter birth weights; mean piglet birth weight and the CV of litter birth weight were also negatively correlated (Table 1).

Several measures at birth showed a consistent pattern of change as the sows aged (Table 2). First and second parity sows produced fewer piglets per litter than middle-aged or old sows $(P<0.001)$. The percentage of pigs born dead increased sharply among old sows; consequently the number of pigs born alive peaked among middle-aged sows and then declined. Number of piglets born was significantly correlated with the percent of piglets born dead $\left(R=0.284 ; F_{1,414}=36.196 ; P<0.001\right)$. Even after adjustment for this trend, the percentage of piglets alive was significantly $(P<0.001)$ lower in litters from gilts than in litters from sows of higher parity, even after adjustment for number of piglets born (Table 2). Birth weight CV was lowest in litters from gilts and highest in litters from old sows, but this difference was not statistically significant after adjustment for number of piglets born (Table 2).

Percent survival to weaning was highest in litters with fewer piglets born alive, high mean birth weight, and a low birth weight CV (Table 1). Percent survival to weaning was particularly low in litters with both low mean birth weight and high birth weight CV (Fig. 1). In the ANCOVA, percent survival to weaning was significantly related to number of live piglets $(P=0.024)$, birth weight $C V(P=0.004)$ and the interaction of birth weight $\mathrm{CV}$ and mean birth weight $(P=0.007)$, but not mean birth weight. Percent survival to weaning was lowest from old sows and highest in litters from 2nd parity sows (Table 2), but parity had no 
significant effect in the ANCOVA after adjustment for number of piglets born alive, mean birth weight, and birth weight $\mathrm{CV}$.

Mean weaning weight was highest in litters with fewer piglets born alive $(P<0.001$ by ANCOVA) and high mean birth weights $(P=0.019$ by ANCOVA), but there was no significant relationship with birth weight $\mathrm{CV}$ or parity (Table 1$)$.

Weaning weight CV was lowest in litters with few piglets born alive, high mean birth weight, low birth weight CV (Table 1), and litters from gilts (Table 2). In the ANCOVA, weaning weight CV was significantly related to number of piglets born alive $(P=0.011)$, mean birth weight $(P=0.008)$, birth weight $\mathrm{CV}(P=$ $0.016)$ and parity $(P=0.027)$.

Because $\mathrm{CV}$ involves dividing the standard deviation (S.D.) by the mean, we repeated the correlation between weaning weight variation and birth weight mean using S.D. in place of CV as the measure of variation; the results showed that weaning weight S.D. was also highest in litters with low mean birth weight $\left(R=-0.192 ; F_{1,232}=8.837 ; P<0.005\right)$.

Low-birth-weight piglets had lower survival (74.5\%) than higher-birth-weight piglets (94.0\%; Table 3). The effect of birth weight class (low- or higher-birth-weight piglets) on percent survival remained significant $(P$ $<0.005)$ even after adjusting for birth weight as a covariate. The difference in percent survival between low- and higher-birth-weight piglets was greatest in litters of 12 or more piglets and in litters from old sows (Table 3). These differences resulted in significant interactions $(P<0.005)$ of birth weight class with both parity and litter size.

Low-birth-weight piglets had lower weaning weights than higher-birth-weight piglets (Table 3). The effect of birth weight class on weaning weights was not significant $(P>0.2)$ after adjustment for birth weight as a covariate. Analysis of variance of weaning weight showed a significant $(P<0.001)$ effect of birth weight, but not of birth weight class, nor of the interactions between birth weight class and sow age and litter size.

Compared to the 193 litters with low-birth-weight piglets, the 41 litters without low-birth-weight piglets had significantly fewer live piglets $(P<0.005$ by ANOVA), higher mean birth weights $(P=0.01)$, lower birth weight CVs $(P<0.001)$, and higher percent survival to weaning $(P<0.01)$, as well as a non-significant trend toward fewer piglets weaned, higher mean weaning weights, and lower weaning weight CVs (Table 4).

Standardized birth weight scores for the 4222 piglets showed a significant negative skew (skewness value $=-0.342 ; P<0.001$ ) with a broader range of values below the mean than above it (Fig. 2). No piglets fell $>3$ S.D. from the litter mean. Of the 129 piglets that fell $>2$ S.D. from the litter mean, 104 were below and 25 were above. Birth weight skewness values, calculated for each litter separately, showed that 310 of the 416 litters (74.5\%) were negatively skewed (Fig. 3), with a mean skewness value for all litters of -0.358 . In 45 litters $(10.8 \%)$, birth weight distribution differed significantly $(P<0.05)$ from normal. The mean skewness value for these 45 litters was -0.750 .

\section{Discussion}

The present study found that high birth weight variation, particularly in litters of low mean birth weight, was associated with low percent survival, independent of litter size and parity. Results from both observational studies (Pettigrew et al., 1986; English and Smith, 1975) and the experimental data of English et al. (1977) suggest that birth weight variation is a major contributor to poor pre-weaning survival. Our results are consistent with this hypothesis. Nonetheless, there are often conflicting results. Van der Lende and de Jager (1991) found that birth weight distribution had no significant effect on pre- 
weaning survival after correction for litter size. Our own earlier study (Milligan et al., 2001a) found that cross-fostering at birth to minimize birth weight variation did not significantly improve pre-weaning survival, although there was a weak tendency in that direction. However, that study excluded very light and unhealthy piglets, litters with more than 12 piglets, and litters raised by sick sows. Although suggestive, our present analysis of birth weight variation does not allow us to conclude that high-birthweight variation by itself will result in low survival; small piglets are thought to be at greater risk of death than large piglets (English, 1998), and litters with highly variable birth weights may simply have more very light piglets with a high risk of death.

Fig. 2. Birth weights of 4222 piglets expressed in terms of S.D. from their respective litter means.

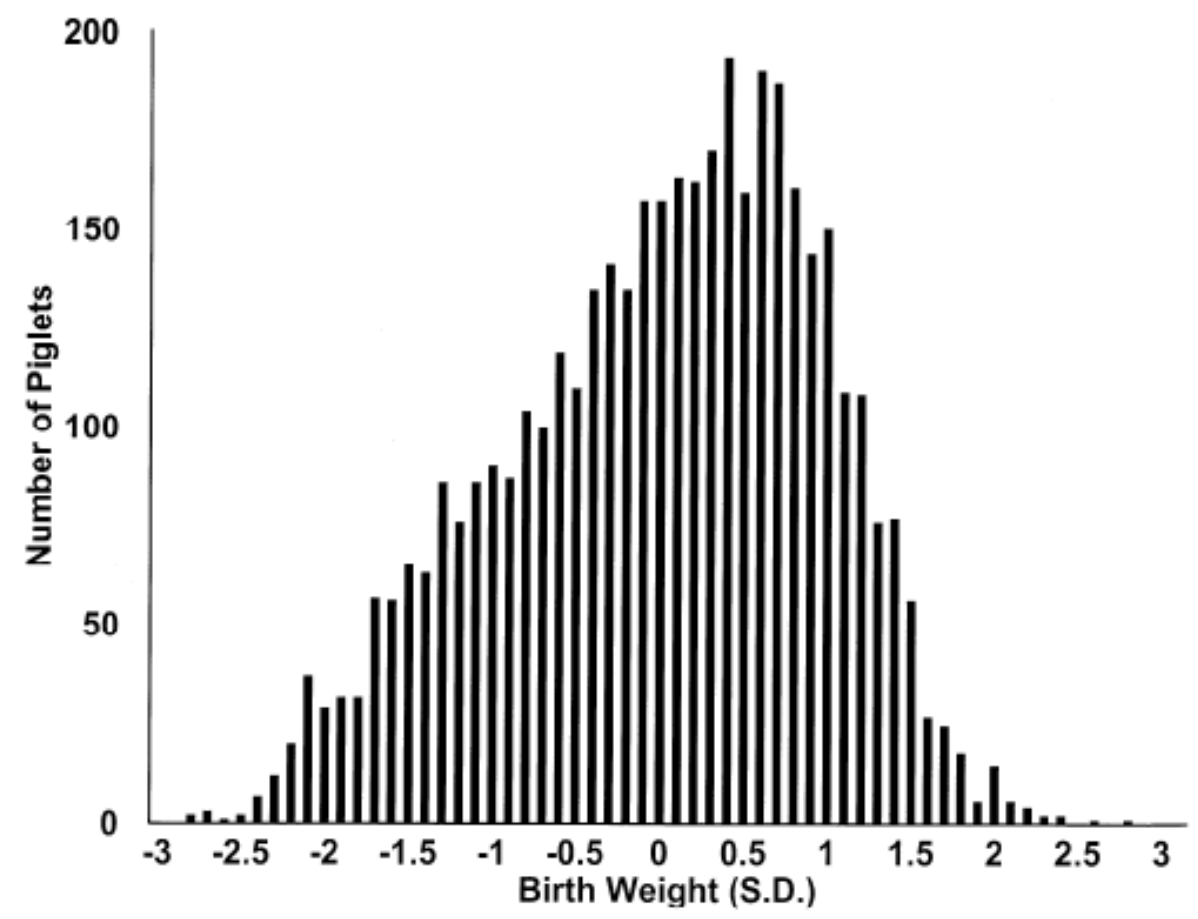

Compared with heavier litter-mates, low-birth-weight piglets take longer to consume colostrum, consume less colostrum, and are more susceptible to chilling and crushing by the sow (Cutler et al., 1999). These early differences can have a significant impact on later survival and weight gain of low-birth-weight piglets (Hoy et al., 1994, 1995; Leenhouwers et al., 2001). Because our 'birth weights' were recorded some hours after birth, the deaths and weight gains that occurred in the first hours are not captured in the data. Thus, pre-weaning deaths were likely slightly underestimated and the difference in birth weight between the heavier and lighter litter-mates were likely slightly overestimated in this study. However, 'birth weights' in this study were obtained at the time most producers would process litters and make management decisions such as cross-fostering. Hence, the data are relevant to management decisions, as well as providing close approximations to true birth weight and survival. Furthermore, the timing of birth weight measurements is comparable to that of many other studies of birth weight and birth weight variation (Fraser et al., 1979; Fraser and Thompson, 1986, 1991; Thompson and Fraser, 1986, 1988; Gardner et al., 1989; Van der Lende et al., 1990; Robert et al., 1995).

There was a significant trend for piglets that fell within the low-birth-weight class to have a higher risk of death than higher-birth-weight piglets, even after adjustment for actual birth weight. A similar conclusion was reached in a study comparing light pigs raised in control or in litters cross-fostered to produce litters 
with uniform birth weights (Marcatti Neto, 1986; but see Aherne, 1999). We also found that piglets in the low-birth-weight class had particularly low survival in larger litters and litters from sows of sixth parity or older than piglets in the higher-birth-weight class. Small piglets are expected to be at greatest risk of death in large litters because of the large number of competitors, and in litters of older sows because of more variable access to functional teats (English et al., 1977; Cutler et al., 1999). In our previous study, where the difference in birth weight of light and heavy litter-mates was exaggerated by cross-fostering, the results showed only a slight improvement in survival by fostering low-birth-weight pigs to litters of similar birth weight (Milligan et al., 2001b); however, as noted above, that study excluded very light and unhealthy piglets, litters with greater than 12 piglets, and sick sows.

Fig. 3. Distribution of litter skewness values in the birth weights of 416 litters.

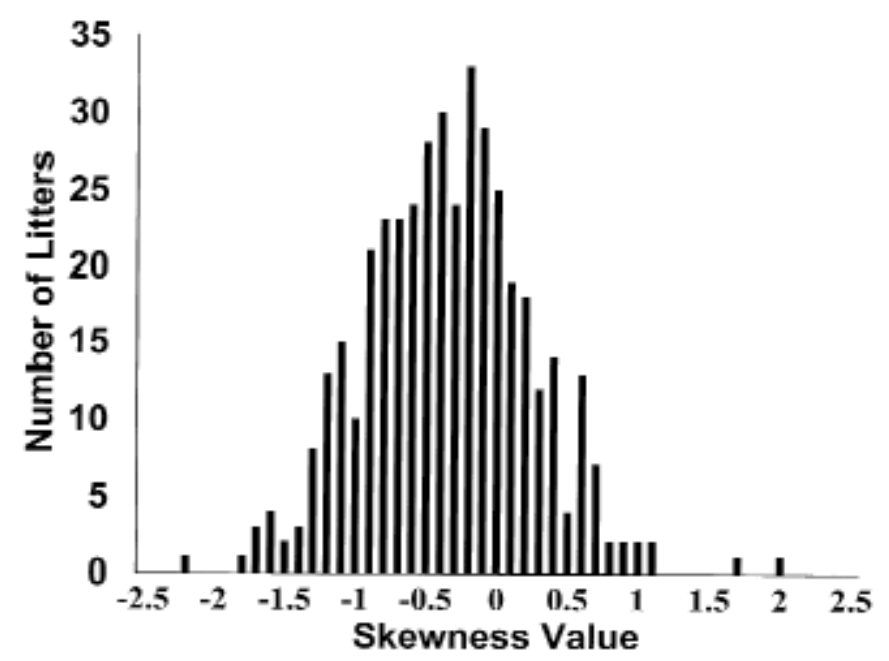

Birth weight variation was not a significant predict tor of mean piglet weaning weight. This result is similar to correlation studies (e.g. Pettigrew et al., 1986) and one experimental study (Milligan et al., 2001a) that did not find a significant relationship between birth weight variation and mean piglet pre-weaning weight gain. Consistent with previous studies, the present study also found a negative correlation between the mean weaning weight of a litter and litter size, and a positive correlation between mean weaning weight of a litter and mean birth weight. The low mean weaning weight of piglets in large litters was likely due to the reduction in milk available per piglet. Sows with larger litters produce more milk but the extra milk is not proportional to the number of extra piglets (Auldist et al., 1998). The effect of mean birth weight on mean weaning weight may be due in part to the ability of large piglets to stimulate teats to produce more milk than small piglets (Thompson and Fraser, 1986; King et al., 1997).

Piglets that fell within the low-birth-weight classification did not gain less than piglets of similar weight that did not fall within this classification, even within large litters and litters raised by old sows. These results, along with those of Milligan et al. (2001b), bring into question the hypothesis that low-birth-weight piglets are at a competitive disadvantage with regard to pre-weaning weight gain, when raised with similar-sized litter-mates compared to heavier litter-mates (English, 1998; English and Morrison, 1984). In an earlier study, piglets of medium birth weight gained less weight when assigned to litters with heavier litter-mates than when assigned to litters with lighter litter-mates (Fraser et al., 1979). Cross-fostering low-birth-weight pigs to create litters of similar birth weight has also been shown to improve weight gains of low-birthweight piglets in one study (Marcatti Neto, 1986) but not another (Aherne, 1999). This is obviously an area that requires further research. 
Litters with more variable weights at birth continued to have more variable weights at weaning, as noted by Thompson and Fraser (1986) and Milligan et al. (2001a). Individual variation in teat productivity (Fraser et al., 1992) can introduce variation in weight gain, while differences in a piglet's ability to stimulate and/or drain teats (Algers et al., 1991) tend to exaggerate initial differences in piglet weights. Variation in weaning weights is a major concern to the pig producer because it results in increased labor, complicated management, and reduced profits (Roberts and Deen, 1995). If for no other reason, crossfostering to minimize birth weight variation may prove beneficial to the pig producer as a means of reducing weaning weight variation.

Litters with many piglets, low mean birth weight, and older mothers were more likely to have high variation in weaning weight. Variation in milk production between individual teats increases with parity, and the tendency for anterior teats to provide more milk becomes more pronounced in older sows (Fraser and Thompson, 1986; Fraser et al., 1992). Older sows, with more pendulous udders, also experience greater difficulty than younger sows in exposing the more posterior teats at nursing (English et al., 1977). Thus, as parity increased, piglets may have been suckling from teats that were more variable in both milk production and accessibility. In large litters some piglets, especially those with lower birth weight, may also have been required to suckle teats with poor milk production, resulting in more variable weaning weights. Poor weight gains and low survival of light piglets may also be explained partly by the fact that they are born weaker and have more difficulty maintaining body temperature than large piglets (Cutler et al., 1999). In litters with low mean birth weight, the presence of light piglets may explain the tendency of such litters to have low mean wean weights and more variable weaning weights than litters with high mean birth weights.

Older parity sows are often culled because of reduced numbers of piglets born and weaned (D'Allaire et al., 1992). By restricting our analysis to sows that farrowed at least eight times we have likely excluded sows that were culled due to poor performance. As a result, our results may not be applicable to sows with poor performance such as small litter sizes. Nonetheless, we believe our results are important because there is so little known about the effect of parity on the parameters studied and most sows with poor performance are culled anyway. Parity had a significant effect on several birth measures including number of piglets born, number of piglets born alive, percent of stillborn piglets, mean birth weight, and birth weight CV. As in other studies, litter size was greatest from middle-aged sows (English et al., 1977). Increased litter size is likely due to an increase in ovulation rate and embryonic survival with parity (Wrathall, 1971). An increase in percent of stillborn piglets with sow age may be due to a decrease in uterine muscle tone with higher parity, leading to a higher rate of intrapartum deaths (Bille et al., 1974). Intrauterine growth retardation and birth weight variation are evident by 35 days post-implantation and are likely a consequence of foetus spacing (Gama and Johnson, 1993; Van der Lende et al., 1990). Hence, the increase in birth weight between first and second parity litters was likely due to an increase in available uterine space (Gama and Johnson, 1993). The subsequent decline in mean birth weight was likely due to increased litter size and a consequent decrease in uterine space per piglet. As reported by Pettigrew et al. (1986) birth weight variation was highest in middle-aged and old sows.

We found that the majority (75\%) of litters had negatively skewed birth weight distributions. Our results confirm that piglet birth weights within a litter sometimes depart from a normal distribution, almost always because of a wider range of weights below the litter mean. Similar results have been found in pigs and other polytocous species (Van der Lende and de Jager, 1991; Wooton et al., 1983). The greater number of small animals likely reflects a degree of fetal growth retardation for at least some offspring (Perry and Rowell, 1969).

As average litter size has increased gradually over generations with selective breeding, pre-weaning survival has decreased and the number of small pigs per litter has increased (Cutler et al., 1999). In this 
study, litters with low-birth-weight piglets started out with more piglets born alive, but had a lower percent survival (with the majority of deaths being low-birth-weight piglets), and did not wean a significantly greater number of piglets than litters without low-birth-weight piglets. Selection for increased litter size that results in more low-birth-weight piglets may not provide a benefit to the producer unless measures are undertaken to improve the survival of low-birth-weight piglets.

\section{ACKNOWLEDGEMENTS}

We thank the director and staff of the former Centre for Food and Animal Research for their help with this study, and C.E. Dewey, R. Friendship and A. de Grau for valuable encouragement and suggestions. This research was supported by a Natural Science and Engineering Research Council (NSERC) research rant to D.L. Kramer and by Agriculture and Agri-food Canada through funding to the Centre for Food and Animal Research. Financial support for B. Milligan was provided by an NSERC Postgraduate scholarship (PGSB) and an NSERC Strategic Grant awarded to D.L. Kramer, D. Fraser, and D.M. Weary.

\section{REFERENCES}

Aherne, F., 1999. Research spotlights techniques to increase piglet survival. Int. Pigletter. 18, 4-6.

Algers, B., Madej, A., Rojanasthien, S., Uvnäs-Moberg, K., 1991. Quantitative relationships between Suckling-induced teat stimulation and the release of prolactin, gastrin, somatostatin, insulin, glucagon and vasoactive intestinal polypeptide in sows. Vet. Res. Commun. 15, 395-407.

Auldist, D.E., Morrish, L., Eason, P., King, R.H., 1998. The influence of litter size on milk production of sows. Anim. Sci. 67, 333-337.

Bille, N., Nielsen, N.C., Larsen, J.L., Svendsen, J., 1974. Pre-weaning mortality in pigs. 2. The perinatal period. Nord. Vet Med. 26, 294-313.

Cutler, R.S., Fahy, V.A., Spicer, E.M., Cronin, G.M., 1999. Preweaning mortality. In: Straw, B.E., D'Allaire, S., Mengeling, W.L., Taylor, D.J. (Eds.), Diseases of Swine. Iowa State University Press, Ames, IA, pp. pp. 985-1002.

D’Allaire, S., Leman, A.D., Drolet, R., 1992. Optimizing longevity in sows and boars. Vet. Clin. N. Am. Food Anim. Pract. 8, 545-557.

English, P.R., 1998. Ten basic principles of fostering piglets. Pig Prog. 14, 39-41.

English, P.R., Smith, W.J., 1975. Some causes of death in neonatal piglets. Vet. Ann. 15, 95-104.

English, P.R., Morrison, V., 1984. Causes and prevention of piglet mortality. Pig News Info. 5, 369-376.

English, P.R., Smith, W.J., Maclean, A., 1977. The Sow: Improving her Efficiency. Farming Press Ltd, Ipswich, UK.

Fahmy, M.H., Holtzmann, W.B., MacIntyre, T.M., Moxley, J.E., 1978. Evaluation of piglet mortality in 28 two-breed crosses among eight breeds of pig. Anim. Prod. 26, 277-285.

Fraser, D., Thompson, B.K., 1986. Variation in piglet weights: relationship to suckling behavior, parity number and farrowing crate design. Can. J. Anim. Sci. 66, 31-46.

Fraser, D., Thompson, B.K., 1991. Armed sibling rivalry among suckling piglets. Behav. Ecol. Sociobiol. 29, 9-15. 
Fraser, D., Thompson, B.K., Ferguson, D.K., Darroch, R.L., 1979. The 'teat order' of suckling pigs. III. Relation to competition within litters. J. Agric. Sci., Camb. 92, 257-261.

Fraser, D., Thompson, B.K., Rushen, J., 1992. Teat productivity in second lactation sows: influence of use or non-use during the first lactation. Anim. Prod. 55, 419-424.

Gama, L.L.T., Johnson, R.K., 1993. Changes in ovulation rate, uterine capacity, uterine dimensions, and parity effects with selection for litter size in swine. J. Anim. Sci. 71, 608-617.

Gardner, I.A., Hird, D.W., Franti, C.E., 1989. Neonatal survival in swine: Effects of low birth weight and clinical disease. Am. J. Vet. Res. 50, 792-797.

Hoy, S., Lutter, C., Wahner, M., Puppe, B., 1994. The effect of birth weight on the early postnatal vitality of piglets. Dtsch. Tierarztl. Wochenschr. 101, 393-396.

Hoy, S., Lutter, C., Puppe, B., Wahner, M., 1995. Correlations between the vitality of newborn piglets, teat order, mortality, and live weight development up to weaning. Berl. Munch. Tierarztl. Wochenschr. 108, 224-228.

King, R.H., Mullan, B.P., Dunshea, F.R., Dove, H., 1997. The influence of piglet body weight on milk production of sows. Livest. Prod. Sci. 47, 169-174.

Leenhouwers, J.I., de Almeida Júnior, C.A., Knol, E.F., van der Lende, T., 2001. Progress of farrowing and early postnatal pig behavior in relation to genetic merit for pig survival. J. Anim. Sci. 79, 1416-1422.

Marcatti Neto, A., 1986. Effect of crossfostering on piglet preweaning performance. Arq. Brasil. Med. Vet. Zootech. 38, 413-417.

Milligan, B.N., Fraser, D., Kramer, D.L., 2001a. Birth weight variation in the domestic pig: effects on offspring survival, weight gain and suckling behaviour. Appl. Anim. Behav. Sci. 73, 171-191.

Milligan, B.N., Fraser, D., Kramer, D.L., 2001b. The effect of littermate weight on survival, weight gain, and suckling behavior of low-birth-weight piglets in cross-fostered litters. J. Swine Health Prod. 9, 161166.

Perry, J.S., Rowell, J.G., 1969. Variations in foetal weight and vascular supply along the uterine horn of the pig. J. Reprod. Fertil. 19, 527-534.

Pettigrew, J.E., Cornelius, S.G., Moser, R.L., Heeg, T.R., Hanke, H.E., Miller, K.P., Hagen, C.D., 1986. Effects of oral doses of corn oil and other factors on pre-weaning survival and growth of piglets. J. Anim. Sci. 62, 601-612.

Robert, S., Thompson, B.K., Fraser, D., 1995. Selective tooth clipping in the management of low-birthweight piglets. Can. J. Anim. Sci. 75, 285-289.

Roberts, J., Deen, J., 1995. Conformance quality in pig production. Comp. Cont. Educ. Pract. Vet. 17, 1308-1311.

Straw, B.E., Dewey, C.E., Burgi, E.J., 1998. Patterns of crossfostering and piglet mortality on commercial U.S. and Canadian swine farms. Prev. Vet. Med. 33, 83-89.

Tabachnick, B.G., Fidell, L.S., 1989. Using Multivariate Statistics. Harper Collins, Northbridge. 
Thompson, B.K., Fraser, D., 1986. Variation in piglet weights: development of within-litter variation over a 5-week lactation and effect of farrowing crate design. Can. J. Anim. Sci. 66, 361-372.

Thompson, B.K., Fraser, D., 1988. Variation in piglet weights: weight gains in the first days after birth and their relationship with later performance. Can. J. Anim. Sci. 68, 581-590.

Van der Lende, T., de Jager, D., 1991. Death risk and pre-weaning growth rate of piglets in relation to the within-litter weight distribution at birth. Livest. Prod. Sci. 28, 73-84.

Van der Lende, T., Hazeleger, W., de Jager, D., 1990. Weight distribution within litters at the early foetal stage and at birth in relation to embryonic mortality in the pig. Livest. Prod. Sci. 26, 53-65.

Wilkinson, L., 1990. The System for Statistics. SYSTAT Inc, Evanston.

Wooton, R., Flecknell, P.A., Royston, J.P., John, M., 1983. Intrauterine growth retardation detected in several species by non-normal birth weight distributions. J. Reprod. Fertil. 69, 659-663.

Wrathall, A.E., 1971. Prenatal Survival in Pigs. Part I. Ovulation Rate and its Influence on Prenatal Survival and Litter Size in Pigs. Commonwealth Agriculture Bureaux, Slough, UK. 